other oxidizable fuels from the anode. Actually, the presence of multiple fucls (with non-interfering reactions) would enhance the ultimate objective. The presence of a combination of the carbonaceous compounds of Table 2 and/or others would not serve as a limitation of application.

We thank Dr D. Ng of IGT for helpful discussions. This work was supported in part by a US Public Health Service research grant.
S. J. YAO
A. J. Appleby
A. Geisel
H. R. CASH
S. K. WOLFSON, JUN.

Michael Reese Hospital and Medical Center,

and

Institute of Gas Technology,

Chicago.

Received June 30; revised October 2, 1969.

${ }^{1}$ Rao, M. L. B., and Drake, R. F., J. Electrochem. Soc., 116, 334 (1969).

${ }^{2}$ Wolfson, jun., S. K., Gofberg, S. I., Prusiner, P., and Nanis, L., Trans. Amer. Soc. Artifuial Internal Organs, 14, 198 (1968).

${ }^{3}$ Iozner, E. L., Winkler, A. W., Taylor, F. H. L., and Peters, J. P., J. Clin. Invest., 20, 507 (1941).

4 West, R., and Clarke, D. H., J. Clin. Invest., 17, 173 (1938).

\section{Isolation from Faeces of Cells capable of Transferring R-factors at a Derepressed Rate}

Mutant strains of enteric bacteria that carry a derepressed $R$-factor have bcen isolated during laboratory experiments. These strains are characterized by the production of sex-pili by the majority of the cells in the culture and by the cells' ability to transfer their $R$-factors to $R^{-}$ recipients at high frequency. Transfor rates per donor cell of $10^{-1}$ to $10^{-2}$ often occur, as compared with a rate of transfer from a repressed strain of about $10^{-4}$ to $10^{-5}$ (refs. 1-3).

During a recent survey of antibiotic sensitivity patterns and incidence of $R$-factors among the bacteria of the gut flora of healthy children, we isolated a strain of Escherichia coli that was capable of transferring its $R$-factor to an $R$-recipient at a frequency about 1,000 -fold higher than is normally encountered among natural isolates of $R^{+}$ bacteria. This observation suggested that derepressed $R^{+}$strains might be encountered in natural conditions. Further, their high transfer potential might make them an important rescrvoir of transferable antibiotic resistance determinants in the gut.

Faeces from healthy children in the Bristol area were examined by estimating the total viable count in acrobic conditions in MacConkey's agar, and also the viable count of the organisms resistant to antibiotics incorporated into plates of MacConkey agar at a concentration of $25 \mu \mathrm{g} / \mathrm{ml}$. The antibiotics were tetracycline, ampicillin and streptomycin. The resistant clones were then examined for their ability to act as donors of $R$-factors by a plate method which tests the transfer of $R$-factors quantitatively ${ }^{4}$.

So far, fifty-four faecal samples have been examined by these techniques and twenty-seven were found to contain resistant organisms. From these twenty-seven samples, thirty-seven resistant strains were isolated. Twentyeight of these contained $R$-factors capable of transferring resistance to one or more of the antibioties used in the original exlture of organisms from the faeces. In all but one of the samples the resistant organisms seemed to bo typical repressed $R^{+}$strains; that is, they acted as a source for transfer of the $R$-factor with a probability of less than $10^{-4}$. This is a typical rate of transfer of a repressed
$R$-factor (see $R$-factor $R 1$ in Table 1 ). But in one case, a tetracycline resistant strain was found to transfer its $R$-factor at high frequency. In this case the faecal sample contained $6 \times 10^{6}$ aerobic bacteria (capable of growing on MacConkey's agar) per $\mathrm{g}$ of faeces and, of these, $3 \times 10^{4}$ organisms/g were resistant to tetracycline. Further examination of three tetracycline resistant colonies from this sample showed that they were capable of transferring the tetracycline resistance gene to the recipient with an approximate frequency por donor cell of between $10^{-1}$ and $2 \times 10^{-2}$. Stock repressed and derepressed $R$-factors gave values of $5 \times 10^{-5}$ and $10^{-1}$ respectively in the same conditions (see Table 1).

Table 1. STATISTICS OE RESISTANCE TRANSFER

$\begin{array}{cccc}\text { Donor } & \begin{array}{c}\text { Number of } \\ \text { resistant cells } \\ \text { tested (poten- } \\ \text { tial donors) }\end{array} & \begin{array}{c}\text { Number of } \\ \text { recipients that } \\ \text { received } \\ \text { resistance }\end{array} & \begin{array}{c}\text { Frequency } \\ \text { of transfer } \\ \text { per donor } \\ \text { cell }\end{array} \\ \begin{array}{c}\text { Stock culture containing } \\ \text { factor } R 1 \text { (repressed) }\end{array} & 20,000 & 1 & 5 \times 10^{-5} \\ \begin{array}{c}\text { Stock culture containing } \\ \text { factor } R 1-19 \text { (derepressed) }\end{array} & 2,000 & 195 & \sim-1 \times 10^{-1} \\ \text { Culture } C 491 \text { from faeces: } & & & \\ \text { Colony } A & 2,000 & 67 & \sim 3.5 \times 10^{-2} \\ \text { Colony } B & 2,000 & 46 & 2.3 \times 10^{-2} \\ \text { Colony } C & 2,000 & 170 & 8.5 \times 10^{-2}\end{array}$

When cells of the deropressed isolate were plated on non-selective media, they gave rise to colonies of two sizes. Both types of colony still carried the $R$-factor, as could be shown by transfer of tetracycline resistance. Cells from the small colonies transferred with a frequency of about $5 \times 10^{-2}$ and were still derepressed. Cells from the large colonies, however, transferred at a frequency per donor cell of about $10^{-5}$ and were therefore now carrying the $R$-factor in the repressed state. Recloning of the cells in the large and small types of colony showed that the small derepressed colonies always contained a high proportion of repressed cells which gave rise to large repressed colonies; on the other hand, colonies that were initially large could not be shown to contain any derepressed cells giving rise to small derepressed colonies. This bchaviour meant that cultures of this naturally occurring derepressed strain tended to revert to the repressed state unless steps were taken continually to re-isolate derepressed variants.

All the experimental evidence available suggests that it is only the derepressed cells of an $R^{+}$culture that are capable of acting as donors in an $R$-factor transfer. The presence of a naturally occurring derepressed strain therefore provides a particularly potent reservoir of $R$. factors for transfer to any superinfecting pathogens. It is even possible that, in practice, only strains of organisms that are in this derepressed state are of clinical importance in infectious drug resistance.

We were unable to obtain more specimens from the child who produced this interesting strain, or specimens from other members of her family. Information from the child's general practitioner showed that she had recently been given a course of sulphonamides but had received no tetracycline.

We thank the Medical Research Committee of the Bristol Royal Hospitals for a grant in support of our work.

Patricia A. Let

K. B. LiNTON

Department of Bacteriology,

University of Bristol.

Received August 28, 1969.

' Anderson, E. S., and Lewis, M. J., Nature, 208, 843 (1965).

${ }^{2}$ Lewis, M. J., Lancet, ii, 953 (1967).

${ }^{3}$ Meynell, L., Meynell, G. G., and Datta, N., Bacteriol. Rev., 32, 55 (1968).

'Tee, P. A., and Richmond, M. H., J. Bacteriol. (in the press) (1969). 